\title{
Mobile Payment: Towards a Customer-centric Model
}

\author{
Krassie Petrova \\ Auckland University of Technology, 55 Wellesley Str. East, Auckland, New Zealand \\ krassie.petrova@aut.ac.nz
}

\begin{abstract}
Mobile payment normally occurs as a wireless transaction of monetary value and includes the initiation, authorization and the realization of the payment. Such transactions are facilitated by purpose-built mobile payment systems that are part of the service infrastructure supporting the functioning of mobile business applications. A number of stakeholder groups may be involved in concluding a mobile payment transaction, among them customers, mobile operators, financial institutions, merchants, and intermediaries. In this paper, mobile payment systems are characterised from the point of view of the stakeholder groups. Building on existing work, a supply and demand model for the investigation of mPayment services is presented, and applied to a case study.
\end{abstract}

Keywords: mobile payment, mPayment, mobile commerce, stakeholders, value chain, customer-centric, adoption.

\section{Introduction}

Mobile payment (mPayment) can be defined as a wireless transaction of monetary value which includes payment initiation, payment authorization, and payment realization. It occurs between a customer and a service or product seller (merchant). The transaction is carried via a mobile device connected to a mobile subscriber network such as a mobile phone. mPayment systems can be characterised using a number of defining features the most important of which are: the transaction amount, the payment settlement mechanism, and the mPayment supporting technology [1-4].

With respect to the transaction amount, an mPayment is either a macro-or micropayment. A micro-mPayment is normally less than US $\$ 10.00$, and is typically used to pay for mobile content (e.g. a mobile game). It is usually facilitated by a Mobile Network Operator (MNO) or a Mobile Subscription Service Provider (MSSP) through the billing mechanism. Macro-payments are larger and may need proper authorization by a bank or another financial institution; they are normally facilitated by a payment system set in place by the MNO, by a bank, or by a third party such as a Mobile Payment Solution Provider (MPSP) [1-2].

With respect to the payment settlement mechanism, mPayments can be classified as subscription account based (where the transaction amount is debited from or billed to the mobile subscriber' account), and card-based (the transaction amount is debited or billed to a credit/debit card) [4]. An example of a subscription-based mPayment is paying for a parking space at the point of parking. Online shopping using mobile ac- 
cess to the Internet illustrates the second type of mPayment. Both mechanisms can be used for either a micro- or macro-payment.

Depending on the type of the supporting technology, mPayments are classified as contactless, and remote. 'Contactless' (or 'proximity') mPayments are conducted with the customer physically present at the point of sale and can be 'manned' (or 'face-toface'), or 'unmanned' (or 'machine-to machine', for example buying refreshments from a vending machine). Proximity payments require an interface between the mobile phone and the merchant's payment terminal. Transactions carried remotely over the network (for example, downloading a news article) are referred to as 'over the air' (OTA). Conducting eCommerce over the mobile Internet and transferring funds are examples of OTA [5-7].

Even a brief overview of mPayment transaction types and settlement and technology characteristics shows that a significant number of market players can be involved in bringing an mPayment service to the customer. The number grows when mPayment is considered as an enabler of another mobile commerce (mCommerce) service. Third parties such as intermediaries may also get involved, for example to bundle a mobile service with a payment service or to provide customer authentication and payment authorization [2], [4], [8].

There is some evidence in the literautre to indicate that while mobile device penetration in New Zealand is suffciently high and on par with other developed countries, mPayment adoption and spread are still lagging behind (somewhat similar to Nordic countries in 2001-2002) [2], [8],[9]. The processes of mPayment acceptance and adoption have been studied widely and factors affecting consumer decisions to use mPayment and their managerial implications have been identified. However the dynamics of the process of meeting customer needs and preferences (demand) by the supply (the gammut of mPayment industry players) has not been studied in depth. This paper aims to propose a customer-centric model for the study of the balance between customer-driven and technology -driven mPayment adoption. The model builds on and complements existing models and frameworks found in prior research and industry reports [ $1-19]$ and can be used to investigate directions for increasing mPayment adoption levels.

The paper is organised as follows: The next section provides information about the structure of the mPayment market and identifes the main stakeholder groups. The section following briefly reviews some mPayment models and proposes a customercentric model. The implications for future research and development are discussed in the concluding section of the paper.

\section{The mPayment Market}

An mPayment transaction involves a customer, an entity offering a mobile service (called further Mobile Business Service Provider - MBSP), and the MNO who facilitates the transaction across all stages and may be actively engaged both in authorisation and completion. Banks and financial institutions (BFIs) may also be involved in transaction authorisation and completion. The MPSP participates in mPayment sce- 
narios based on a cooperative business model. Auxiliary participants (e.g. a Mobile Internet Services Provider) may also be involved.

The players listed above interact both with each other and with the customer to facilitate an mPayment transaction from initiation to completion. As a result, the mechanisms for sharing the revenue stream become complex and costly, requiring the development and adoption of standards and protocols across the mPayment market. This may in turn lead to the diminishment of the mPayment value proposition and inhibit growth [4], [8].

\subsection{Mobile Payment Market Growth and Segmentation}

At present the mPayment market is dominated by Japan (close to $80 \%$ ), however a global growth up to US $\$ 150$ billion in 2012 with transaction revenues up to US\$ 37.1 billion [9], [12]. According to [9], three particular mPayment market segments will exhibit growth in the future: mobile contactless payments, online shopping, and money transfers.

Mobile contactless payments are expected to grow from US\$3 billion in 2007 to US\$52 billion in 2012. These micro- or macro-transactions are conducted through a mobile payment system, developed by an MPSP and based on an alliance, or another cooperative revenue sharing formation among industry players. Initiatives such as "Pay-Buy" and "Payez Mobile" for example require collaboration among MNOs, BFIs, mobile phone manufacturers, MBSPs, and customers) [6-7]. Geographically, contactless payments at the point of sale are expected to grow across the European Union (EU), the USA, Japan, and in some Asia-Pacific countries [5 - 7], [12].

Mobile money transfers are expected to grow from US\$1 billion in 2007 to US \$58 billion in 2012). These transactions involve BFIs and possibly additional stakeholders such as local convenience store owners who may act as cash providers to customers in a remote area in a developing country. Mobile transfers are normally remote macropayments, settled via an account at a bank and/or at an intermediary.

Mobile online shopping (which requires access to the Internet via a mobile device) is a basic eCommerce business-to-consumer model in which the customer accesses the Internet via a handheld device connected to a MNO. The expected growth is from US\$8 billion in 2007 to US\$41 billion in 2012. Both micro- and macro -payments can be made. Mobile ISPs are involved as intermediaries.

The highlighted trends emphasise growth across the spectra of transaction type, technology and settlement method, indicating that all mPayment market players involved in creating and offering mPayments services will continue to be active. The next subsection groups the mPayment market players into main stakeholder groups.

\subsection{Mobile Payment Stakeholder Groups}

mPayment services and systems require a high level of interoperability and compatibility across devices, network platforms, and software applications; depending on their market role, stakeholders may operate independently or participate in cooperative models. The mCommerce framework proposed in [16] can be used to identify the 
main stakeholder groups with regard to their role in driving the processes of spread and adoption of mPayment. Three different categorise emerge (Table 1): Primary mPayment providers (mPayment Technology Enablers, or MPTEs), secondary mPayment providers (mPayment Service Enablers, or MPSEs), and mPayment adopters (MPAs).

Table 1. The main stakeholder categories involved in mPayment development, deployment and adoption.

\begin{tabular}{|c|c|c|}
\hline $\begin{array}{l}\text { Primary mPayment Pro- } \\
\text { viders: Technology En- } \\
\text { ablers (MPTEs) }\end{array}$ & $\begin{array}{l}\text { Secondary mPayment Pro- } \\
\text { viders: Service Enablers } \\
\text { (MPSEs) }\end{array}$ & $\begin{array}{l}\text { mPayment Adopters } \\
\text { (MPAs) }\end{array}$ \\
\hline 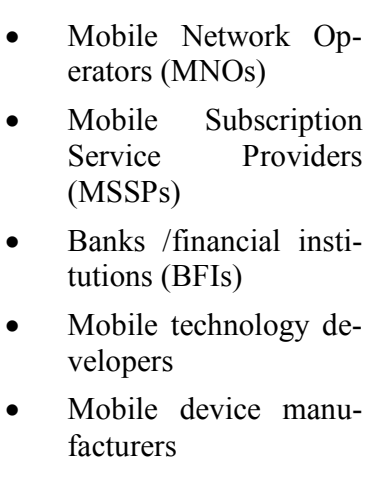 & $\begin{array}{ll}\text { - } & \text { Mobile content develop- } \\
\text { ers } \\
\text { - } \\
\text { Mobile content aggrega- } \\
\text { tors } \\
\text { - } \\
\text { Business and organiza- } \\
\text { tions accepting mobile } \\
\text { payment (MBSPs) } \\
\text { - Intermediaries (mobile } \\
\text { payment aggregators, se- } \\
\text { curity providers) } \\
\text { Mobile Payment Solution } \\
\text { Providers (MPSPs) }\end{array}$ & 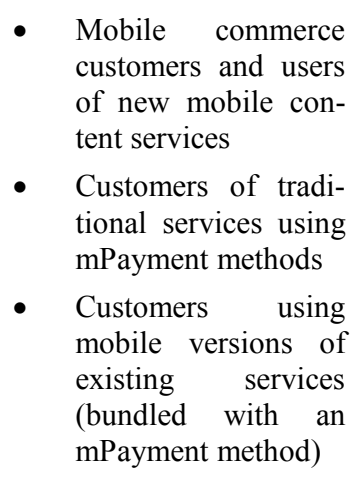 \\
\hline
\end{tabular}

The first group includes MNOs, MSSPs, BFIs, mobile technology developers, and mobile device manufacturers. These stakeholders enable technologically mPayment and are posed to benefit directly from each mPayment transaction. Therefore, MPTEs may be considered as playing a fundamental role in the development of mPayment services, and driving the mPayment market based on technological development, often through industrial alliances [1], [3-8], [10], [12-13].

The second stakeholder group comprises market players who provide mPayment as either a service bundled with an mCommerce service, or as a payment mechanism for other goods and services [11]. More specifically, participants in the MBSPs subgroup include: merchants and organizations using mPayment at the point of sale (POS) or remotely, either for an existing product or service such as paying for a bus ticket using a mobile phone, or for a new 'pure mobile' service (such as a mobile game download). MBSPs benefit from retaining their existing customer base and from generating new revenue streams through innovative services. Intermediaries (for example, security and identification providers, and payment aggregators) and MPSPs are businesses which provide mPayment services through their core business model [4-5], [8], [18]. The MPSE stakeholders drive the mPayment market based on business development: mPayment services are deployed in their respective business models because of the technological drive of the primary mPayment providers.

The third category includes customers and end-users who participate by adopting mPayment. Studies about customer motivation have identified motivational and deci- 
sion making factors, and critical success factors and barriers to acceptance and adoption. The customer subgroups in the table refer to the target groups of mCommerce customers, and to customers who use contactless payment for traditional or innovative services [11]. Customers have been found to be willing to accept mPayment services depending on the context of the offer but have not created a strong demand for them [8-9], [11], [13-15], [17].

It may be concluded that mPayment at present is still technology- rather than customer-driven, mostly through initiatives by the primary mPayment providers. Servicedriven mPayment occurs in areas such as new mobile content services and applications (e.g. mobile entertainment [21]), and 'mobile versions' of existing services (for example, mobile betting [22]). Despite opinions such as "In our contemporary society, being mobile, or simply capable of playing with mobility options, thanks to adequate infrastructure, devices, skills and knowledge, is generally associated with a positive, dynamic and seemingly indispensable form of lifestyle as well as productive behaviour" [23, p. 79], customers are yet to create a strong demand for mPayment services.

\section{$3 \quad$ Modelling mPayment}

A number of models have been used in the literature to represent the supply side of mPayment and identify the value proposition of mPayment. Value chain models, service models (scenarios), and business models involve the players in the technology enablers and service enablers stakeholder groups [1-7], [10], [12-13], [25]. The demand side (customers and end-users) has been modelled through acceptance and adoption models to identify critical success factors and barriers to adoption [11], [1417], [25-30]. This section reviews the relevant findings and proposes a model for the study of the dynamic relationships between the stakeholder groups and between mPayment adopters and stakeholders.

\subsection{Supply Side Studies: mPayment Value Chain and Scenarios}

The value chain approach has been used to identify the players involved in certain mPayment scenarios, and their roles [1], [19]. To capture the complexity of the interactions, using a web of value chains rather than a linear representation has been also suggested [24].

The interactions between the players have been modelled using scenarios and use cases [13], [25]. A set of seven disjoint use cases identified in prior work was used in [13] to derive the important characteristics of the mPayment value proposition with respect to customers: geographical applicability, payment guarantee, mobile market integration, and payment amount.

A dichotomy of 'carrier-centric' and 'payment solution-centric' models of mPayment scenarios is proposed in [9]. Their analysis of the development of mPayment services across the market place indicates that mPayment has evolved from a stage where MNOs act also a MBSP and MPSP (Figure1a) to a stage where mobile busi- 
ness services are unbundled from mobile data, and MBSPs have started to drive the mPayment market (Figure 1b).

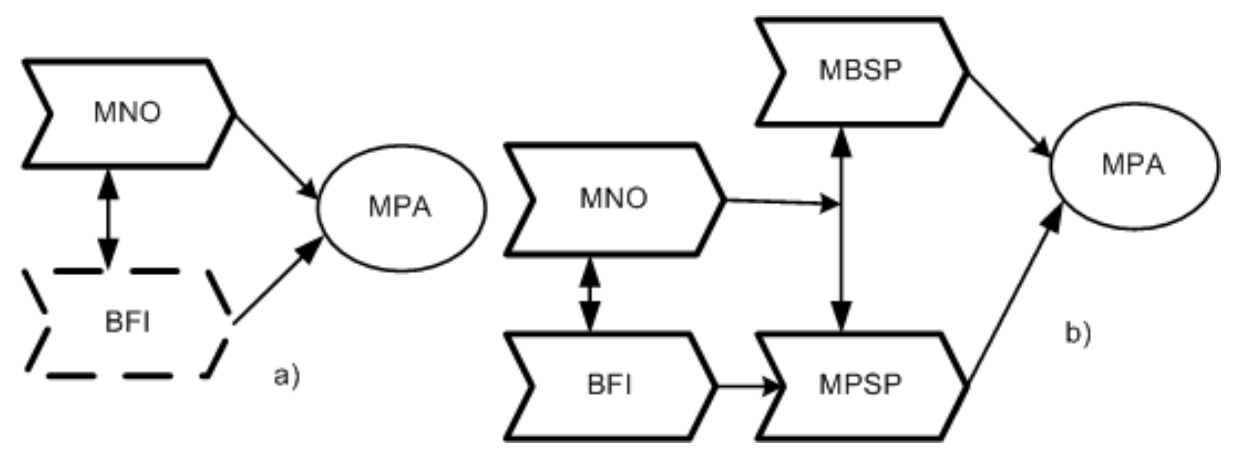

Fig. 1. The evolution of mPayment (based on [9-10]).

\section{2 mPayment Adoption and Acceptance}

As summarised in [19] the demand side of mPayment (customers and end-users) has been studied empirically and qualitatively through models such as TAM (Technology Acceptance Model) and TTF (Task-Technology Fit), including participants from a country or a region [3], [8], [11], [14-15], [25-30]. These studies have identified a number of mPayment factors influencing negatively or positively customer adoption and use (Figure 2).

Cost, convenience, and added value were repeatedly identified as critical mPayment success factors. Direct cost (customer paying an additional charge to use mPayment in a specific scenario and customer paying for mobile data transport) has been shown to be a barrier to the intention to use, also because of the abundance of other, less costly methods already available. The enabling cost (customer needing a mobile device supporting the technology used for mPayment) may also become a barrier but its importance may vary depending on the customer demographics [2], [8], [14], [26-27]. Convenience (related to 'perceived ease of use' in TAM) refers to the degree of effort needed by the customer to execute a payment (including registration, access, device usability, time needed to complete the transaction) [2], [8], [11], [1415], [17]. Value added (related to 'perceived usefulness' in TAM) refers to the additional benefits for the customer when using mPayment such as saving time, saving the need to interact at POS, replacing the need to carry cash or use multiple plastic cards) [8], [11], [14-15], [17], [27].

Four additional characteristics have been identified: Mobility support, tasktechnology fit, trust and security. Customer mobility support refers to the ability of the customer to use mPayment across geographical locations, including internationally, and in use situations where mPayment becomes the only viable method (i.e. the ability to transact not only 'any time' but 'anywhere')[14], [17]. Task-technology fit refers to the extent to which mPayment technical features match both the customer ability to operate the device in order to pay, and the suitability of mPayment for the 
particular service or product [11]. Security and trust refer to the perceptions of the customer with regards to the non-repudiation of the mPayment transaction [11], [14]. The importance if these factors have not been established with a great degree of certainty. While mobility support and task-technology fit have been found to influence positively the intention to use, security and trust have not been found to be critically important.

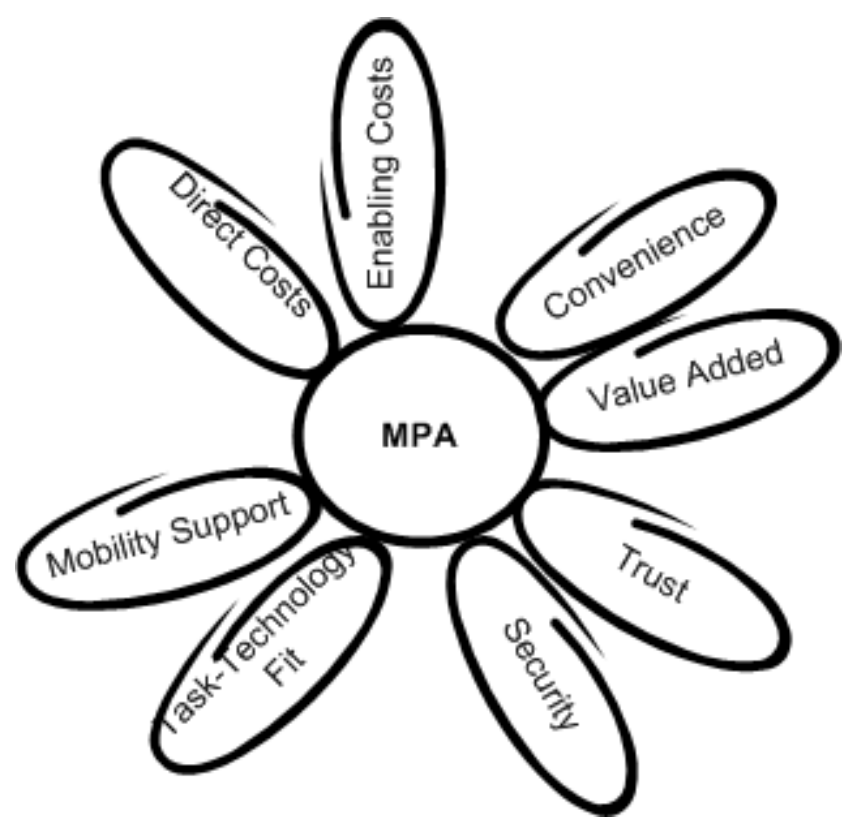

Fig. 2. mPayment characteristics influencing customers and end-users

Three areas of customer demand emerge from the discussion of he critical success factors and barriers to mPayment: a) Demand for quality of service (convenience, value added, mobility support, task-technology fit; b) Demand for cost-effectiveness (direct and indirect costs), and c) Demand for a regulated environment (security and trust). Quality of service plays a critical role in customer acceptance, however the decision to adopt is a tradeoff between value and cost. The environment in which mPayment occurs is normally perceived to be trustworthy, partially because customers have already established relationships with some of the players (e.g. with the $\mathrm{MNO})$.

\subsection{A Customer-centric Demand and Supply Model}

As mentioned earlier, mPayment adoption has not progressed according to the forecasts in the past. In the previous subsection MNOs and possibly BFIs were identified as drivers at the initial stage of mPayment; MPSPs become the main driver of the market as mPayment develops further, with MBSPs also becoming active as they start 
their own adoption process. In [11] the authors note, "Mobile payments represent an extremely interesting paradox in the world of mobile telecommunications, still not showing success in most markets. Customer acceptance turned out to be a decisive factor". Therefore placing an emphasis on customers as potential drivers of mPayment may bring a new perspective to the study of mPayment development and spread.

As customer acceptance is critical to the success of mPayment, the two other stakeholder groups need to develop and offer services meeting the demands of the MPA stakeholder group identified above: An mPayment service of high quality and at a cost which the customer will be willing to pay. The MPTE/MPSE stakeholders need to engage in cooperative business models for service provision and revenue sharing which will allow meeting customer demand and remaining viable. Figure 3 shows a demand and supply model which can be used to study the dynamics of these processes.

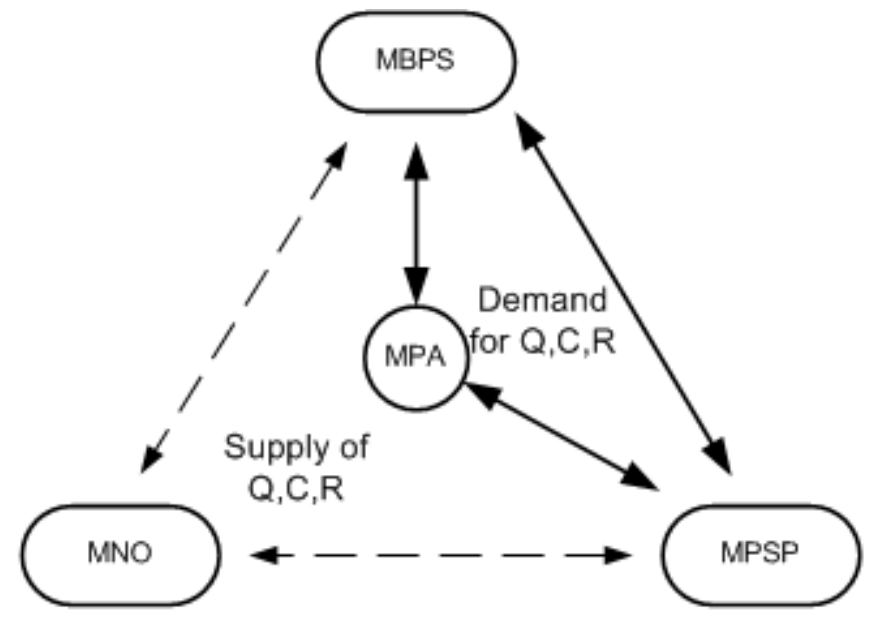

Q- Quality, C- Cost-Effectiveness, R- Regulated Environment

Fig. 3. A Customer-centric demand and supply model

MPAs demands for quality, cost- effectiveness and a regulated environment are directed mainly towards the MBPS participants. However, it is the relationships among all industry players (MNOs, MPSP and MBPS) which underpin both the value and the quality parameters. The demand for a regulated environment is met primarily by the MNO and the MPSP, operating within a local or a regional regulatory framework. The model identifies three main areas of further investigation:

1. How will MBSPs meet customer demand in terms of quality and costeffectiveness? How can customer demand be more accurately predicted and what new services requiring mPayment or bundled with an mPayment option could be developed to satisfy them?

2. How will MPSPs meet customer demand in terms of quality and cost-effectiveness in a regulated environment? How could mPayment become the preferred mode of payment for customers (presuming this is desirable from a customer perspective)? 
3. How will MNOs (and mobile technology providers) support the development of quality mPayment services in cooperation with MBSPs and MPSPs?

In the next section, an mPayment case study is analysed by applying the model to answer the questions above.

\section{The ' TXT-a-park' Case Study}

Customers in some city council owned car parks in New Zealand cities have the choice of paying for their parking by coin, by credit card or by SMS (text messaging). The latter service is known as 'TXT-a-park'. After the SMS-based transaction is completed, the customer receives a ticket from the parking meter. The cost of parking is debited from the mobile network subscriber account [31-33].

Figure 4 shows the supply and demand model for TXT-a-park. MNOs are the two dominating New Zealand mobile operators Vodafone and Telecom Mobile. The MBSP is the relevant City Council. The MPSP is DPS - an established New Zealand eCommerce payment solution developer and provider company.

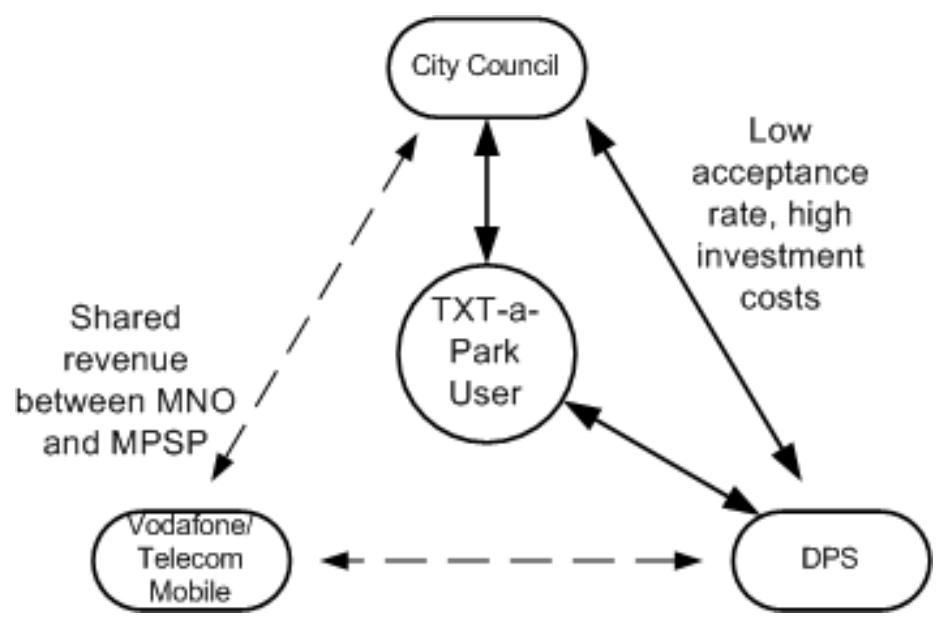

Fig. 4. The 'TXT-a- park' case study customer-centric model

The double arrowed lines in the model show the relationships amongst the model participants. The city council collaborates with the mobile network operators, on one side, and with the payment solution company on the other, in order to set up and offer the service. The payment solution provider facilitates mobile (and credit card) payment and provides and supports the revenue channels for of all participants. The customer pays a regular service cost (parking fee) to the city council. The direct mPayment costs include a surcharge on top of the normal text message cost; the surcharge is shared by the network operator and the payment solution provider.

According to the claims of the mobile service provider, customer demand in terms of quality has been met as the mPayment service is perceived as convenient, and use- 
ful [31]. However, the service does not support mobility as the transaction has to be conducted in the proximity of the payment terminal. There is some evidence to indicate that the cost of the transaction may be perceived as too high by some customers as the level of use seems to vary according to the location of the parking area. This was found in the course of a small project conducted by the author and a student who observed several parking meters and briefly interviewed customers at the spot [34]). It may be surmised that in areas that are more affluent customers are less sensitive towards the extra charge. The transaction environment is perceived as trustworthy: customers trust inherently the MBSP and are aware of the security provisions of the two network operators. In summary, the quality of this service $(\mathrm{Q})$ is high and the regulated environment $(\mathrm{R})$ is supportive of the service however the cost-effectiveness (C) may be low for some customers.

The analysis of the case allows providing some answers to the questions formulated in Section 3.

1. With respect to MBSPs meeting customer demand in terms of quality and costeffectiveness, new valued added services could be offered - for example, extending remotely the validity of the parking ticket remotely as suggested in [12].

2. Increasing the scope of mPayment options by adding payment via a bank account (already implemented on a trial basis for business accounts [34]) addresses the second question - about MPSPs meeting customer demand and increasing the appeal of mPayment as a mode of payment. It may be expected that customers parking while on business duty will be highly motivated to pay direct and have to go through a laborious claim process afterwards.

3. Referring to the question about MNOs (and mobile technology providers) supporting the development of quality mPayment services in cooperation with MBSPs and MPSPs: In this case, the MNOs and the MPSP have negotiated, in return for collaborating with the mobile service provider, to share the total surcharge revenue. As the MNOs are satisfied with their return on investment, it is unlikely that they would come up with a new initiative to promote mPayment (as the mPayment service is not an essential part of their business model).

The brief discussion of the TXT-a park case study demonstrated the applicability of the model proposed earlier to the analysis of an mPayment service: The relationships were substantiated and the questions formulated were addressed. However as only limited data were used conclusions about the generalizability of the customercentric model cannot be made without a further study.

\section{5...Concluding Remarks}

Prior research has addressed some of the relationships in the supply and demand areas in the customer-centric model proposed. The ability of the MNO to provide service matching customer demand has been studied in [17] where the issue of balancing customer needs and the business value proposition of one of the main players in the MPTE stakeholder group is investigated. The study used the critical success factors identified in earlier work to analyze how well wireless technologies would meet customer user requirements. Balancing the needs of MBSPs and the drive by MNOs and 
MPSPs is the focus of [18], where four barriers preventing MBSPs from proactively driving the mPayment market are identified: relative advantage, compatibility, complexity and cost. The customer-centric model introduced and validated here aligns well with the direction of these studies and also with a number of the suggested general mPayment research directions in [19]. It is proposed to use the model to investigate and evaluate mPayment services within the framework of customer requirements, in order to suggest to MBSPs directions for further development meeting customer mobility and lifestyle needs and involving customers as active participants. Further studies may adopt both a quantitative approach to study the perceptions, attitudes and needs of customers, and a qualitative approach to study the needs of MBSPs. A set of measures to evaluate and assess the parameters of the model (quality of service, costeffectiveness and regulatory environment) will need to be developed.

\section{Acknowledgements}

The author would like to thank the anonymous reviewers for the thorough reviews and helpful suggestions and comments.

\section{References}

1. Mobile Payment Forum 1, http://www.mobilepaymentforum.org/pdfs/mpf whitepaper.pdf

2. Kreyer, N., Pousttchi, K., Turowski, K.: Standardized Payment Procedures as Key Enabling Factor for Mobile Commerce. In: Quirchmayr, G., Tjoaa, A. M. (eds.) 3rd International Conference on Electronic Commerce and Web Technologies, pp. 400-409. ACM Press, New York (2002)

3. Valcourt, E., Robert, J.-M., Beaulieu, F.: Investigating Mobile Payment: Supporting Technologies, Methods, and Use. IEEE International Conference on Wireless and Mobile Computing, Networking and Communications, pp. 29-36. IEEE Press, New York (2002)

4. Ondrus, J., Pigneur, Y.: A Disruption Analysis in the Mobile Payment Market. In: 38th Annual Hawaii International Conference on System Sciences, pp. 84c (pp. 10). IEEE Press, New York (2005)

Payment

Forum

2,

http://www.mobilepaymentforum.org/documents/Proximity_Payment_IR_11_0.pdf

6. Payez Mobile, http://www.gemalto.com/press/IntheNews/download/2007/11-09-2007payez_mobile.pdf

7. GSMA, http://www.gsmworld.com/news/press_2007/press07_21.shtml

8. Dahlberg, T., Mallat, N.: Mobile Payment Service Development - Managerial Implications of Consumer Value Perceptions. In: 9th European Conference on Information Systems, pp. 649-657. (2002)

9. Van Bossuyt, M., Van Hove, L.: Mobile Payment Models and Their Implications for NextGen MSPs, J. of Policy, Regulation and Strategy, 9(5), 31-43 (2007)

10. Tong, F., Zhou, X., Liu, S.: The Value Chain of Mobile E-payment. In: International Conference on Electronic Commerce, pp. 880 -882. ACM Press, New York (2005)

11. Pousttchi, K., Wiedemann, D. G.: What Influences Consumers' Intention to Use Mobile Payments? In: LA Global Mobility Round table (2007)

12. Taga, K., Karlsson, J.: Arthur D. Little Global M-Payment Update 2005. http://www.3mfuture.com/articles_epayment/Global_M-Payment-

Report Update Arthur D Little 2005.pdf. 
13. Pousttchi, K., Schiessler, M., Wiedemann, D. G.: Analyzing the Elements of the Business Model for Mobile Payment Service Provision. In: 6th International Conference on Mobile Business, pp. 44 (pp. 8). IEEE Press, New York (2007)

14. Pousttchi, K.: Conditions for Acceptance and Usage of Mobile Payment Procedures. In: 2nd International Conference on Mobile Business, pp. 201-210. University of Munchen (2003)

15. Teo, E.: Inhibitors and Facilitators for Mobile Payment Adoption in Australia: A preliminary study. In: 4th International Conference on Mobile Business, pp. 663-666. IEEE Press, New York (2005)

16. Petrova, K.: Mobile Commerce Applications and Adoption. In: Khosrow-Pour, M. (ed.) Encyclopedia of e-Commerce, e-Government and Mobile Commerce, pp. 771 - 776. Idea Group Reference, Hershey, PA (2006)

17. Zmijewska, A.: Evaluating Wireless Technologies in Mobile Payments - A Customer Centric Approach. In: 4th International Conference on Mobile Business, pp. 354-362. IEEE Press, New York (2005)

18. 18 Mallat, N., Tuunainen, V. K.: Merchant Adoption of Mobile Payment Systems. In: 4th International Conference on Mobile Business, pp. 347-353. IEEE Press, New York (2005)

19. Dahlberg, T., Mallat, N., Ondrus, J., Zmijewska, A.: Mobile Payment Market and Research - Past, Present and Future. In: Helsinki Global Mobility Roundtable (2006)

20. Poulbere, V.: Mobile payment: progressing towards large--scale deployments. Ovum report (2008)

21. Schubert, P., Hampe, J. F.: Mobile Communities: How Viable are Their Business Models? An Exemplary Investigation of the Leisure Industry, Electronic Commerce Research, 6(1), 103-121 (2006)

22. Petrova, K. \& Parry, D.: Mobile Computing Applications in New Zealand. In: Yoo, Y., Lee, J.-N, Rowley, C. (eds.) Trends in Mobile Technology and Business in the Asia-Pacific Region, pp. 153-177. Chandos Publishing, Oxford, UK (2008)

23. 23 Rossel, P., Finger, M., Misuraca, G.: Mobile e-Government Options: Between Technology-driven and User centric, The Electronic Journal of e-Government 4(2), $79-86$ (2006).

24. Akkermans, J. M., Z. Baida, Gordijn, J., Peña, N., Altuna, A., Laresgoiti, I.: Value Webs: Using Ontologies to Bundle Real-World, Intelligent Systems 19(4), 57-66 (2004)

25. Herzberg, A.: Payments and Banking with Mobile Personal Devices, . Communications of the ACM, 46(5), $53-58$ (2003)

26. Dahlberg, T., Mallat, N. , Oorni, A.: Consumer Acceptance of Mobile Payment Solutions - Ease of Use, Usefulness and Trust. In: 2nd International Conference on Mobile Business, pp. 211-218. (2003)

27. .27. Malat, N.: Exploring Consumer Adoption of Mobile Payments - A Qualitative Study. In Helsinki Global mobility Round table (2006)

28. Hort, C., Gross, S., Fleish, E.: Critical Success Factors of Mobile Payments, In: M-Lab. http://www.m-lab.ch/pubs/13 CriticalSuccess Mobile (2002)

29. Wrona, K., Schuba, M., Zavagli, G.: Mobile Payments - State of the Art and Open Problems, LNCS, vol. 2232, pp. 88 - 100, Springer, Heidelberg (2001)

30. Henkel, J.: Mobile Payment: The German and European Perspective, Mobile Commerce, 10(2), $1-22$ (2001). City Council, http://0www.aucklandcity.govt.nz.www.elgar.govt.nz/news/releases/20051214a.asp

32. Wellington City

Council, http://www.wellington.govt.nz/services/parking/onstreet/txtapark.html

33. Fronde, http://www.frondeanywhere.com/txt-a-park/

34. Mehra, R.: Paying for parking with Your Mobile Phone, unpublished. 